\title{
Chloride transport and novel insights into salt-sensitive hypertension
}

\author{
Friedrich C. Luft
}

Published online: 23 February 2013

(C) Springer-Verlag Berlin Heidelberg 2013

Solute-linked carrier 26 (SLC26) isoforms are members of a large conserved family of anion exchangers, many of which display highly restricted and distinct tissue distributions.

Cloning experiments have identified more than ten SLC26 genes or isoforms (SLC26A1-11) [1]. Transport modes mediated by SLC26 members include the exchange of chloride for bicarbonate, hydroxyl, sulfate, formate, iodide, or oxalate with variable specificity. Several members of SLC26 isoforms are expressed in the kidney, including SLC26A1, SLC26A4 (pendrin), SLC26A6, SLC26A7, and SLC26A11. Each isoform displays a specific nephron segment distribution with a distinct subcellular localization. Current data indicate important roles for the SLC26 family in chloride absorption, vascular volume homeostasis, acid-base regulation, and oxalate excretion in the kidney.

Amlal et al. still added another to the list, namely SLC26A9 or Slc26a9 in the mouse [2]. They relied on Slc26a9 "knockout" mice and document that the electrogenic chloride channel/transporter is localized on the apical membrane of principal cells in the renal medullary collecting duct and functions to mediate chloride excretion (Fig. 1). The collecting duct system is the final component of the kidney to influence the body's electrolyte and fluid balance. In humans, the system accounts for $4-5 \%$ of renal sodium and water reabsorption. The principal cells mediate the collecting duct's influence on sodium and potassium balance via sodium channels and

F. C. Luft $(\bowtie)$

Experimental and Clinical Research Center, a joint cooperation between the Charite Medical Faculty and the Max-Delbrück Center for Molecular Medicine, Lindenbergerweg 80 ,

13125 Berlin, Germany

e-mail: luft@mdc-berlin.de potassium channels located on the cell's apical membrane. Aldosterone determines expression of sodium channels with increased aldosterone causing increased expression of luminal sodium channels. Aldosterone increases the number of $\mathrm{Na}^{+} / \mathrm{K}^{+}$-ATPase pumps that allow increased sodium reabsorption and potassium secretion. Vasopressin determines the expression of aquaporin channels on the cell surface. Together, aldosterone and vasopressin let the principal cell control the quantity of water that is reabsorbed. Intercalated cells come in $\alpha$ and $\beta$ varieties and participate in acid-base homeostasis.

Amlal et al. found that Slc26a9 gene-deleted mice exhibit reduced chloride excretion when given a high-salt diet (HSD, $7 \%$ salt) or when subjected to water deprivation [2]. The group had earlier reported on SlC26a9 deletion and relevance to gastric surface epithelial cells, where the carrier mediates $\mathrm{Cl}^{-} / \mathrm{HCO}_{3}{ }^{-}$exchange [3]. If we are willing to believe tail-cuff blood pressure measurements in mice, Slc26a9 gene-deleted mice have substantially higher blood pressures when given "normal-salt" diet (NSD, $1 \%$ salt) and exhibit a further increase in blood pressure after HSD. Of interest is the fact that plasma electrolytes and acid-base balance are normal in Slc26a9 gene-deleted mice. The authors conclude that sodium (as chloride) retention occurs with absence of Slc26a9 and speculates that sodium is reabsorbed via the epithelial sodium channel (ENaC). Numerous Mendelian sodium-transport mechanisms have been implicated in salt-sensitive hypertension, including glucocorticoid-remediable aldosteronism, mutated $11 \beta$ hydroxysteroid dehydrogenase-2, ENAC $\beta$ and $\gamma$ subunit mutations, and with-no-lysine kinase 1 and 4 mutations [4]. To my knowledge, this model is the first example of a faulty (or absent) chloride channel as being responsible for sodiumsensitive hypertension. 
Fig. 1 SLC26A9, the murine Slc26a9 exhibits are large chloride conductance and was also reported to behave as an electrogenic $\mathrm{Cl}^{-} / \mathrm{HCO}_{3}$ exchanger. Schematic diagram of the channel in a principal cell is prepared according to Amlal et al. with SLC26A9 mediating chloride secretion [2]. Aquaporin-2 (AQP2) colocalized with SLC26A9

\section{Principal cell}

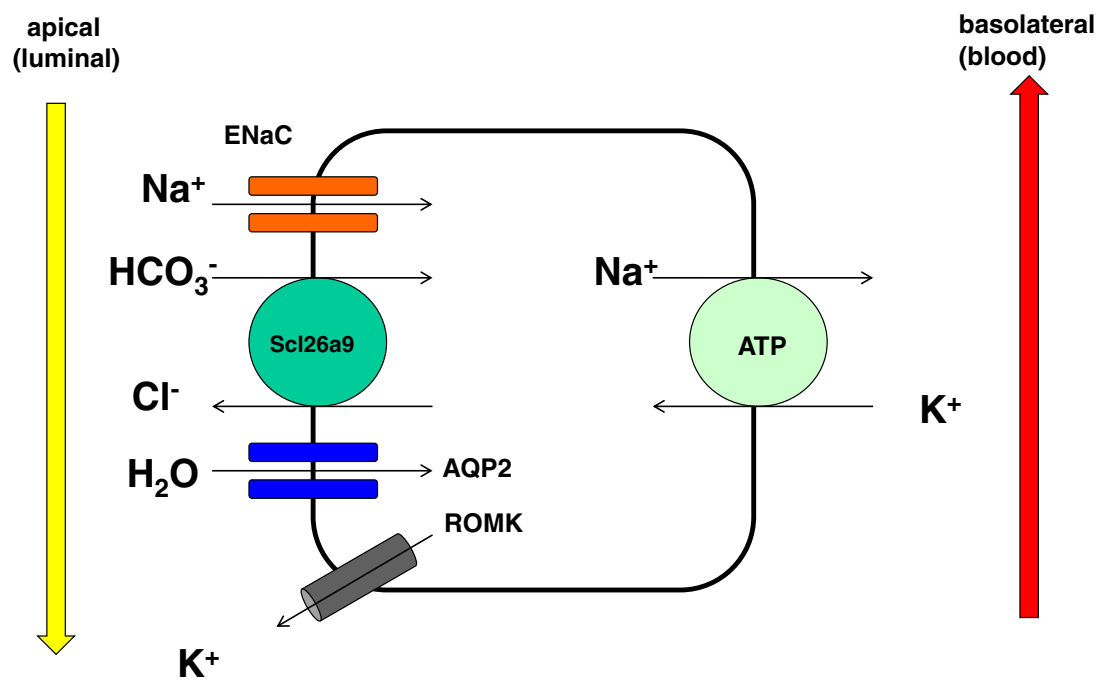

Admittedly, mouse metabolic cage work is fraught with confounders. Nevertheless, with the initiation of HSD, the Slc26a9 gene-deleted mice excreted about $1 \mathrm{mmol} /$ day less chloride and sodium for the first $24 \mathrm{~h}$, after which balance appeared to be restored. Assuming absolutely no sodium or chloride nonosmotic storage and iso-osmolality in all compartments, such an electrolyte accumulation would be expected to increase volume by about $7 \mathrm{ml}$ and body weight by $7 \mathrm{~g}$. We are not given the weights after HSD; however, this state of affairs probably did not occur. So where could the sodium and chloride have gone in these salt-sensitive Slc26a9 gene-deleted mice? The authors discuss tonicity-responsive enhancer binding protein (TonEBP), an osmotically activated transcription factor also known as NFAT5 that is capable of increasing the expression of the serum- and glucocorticoid-inducible kinase (SGK1). Such an action could have played a role in restoring sodium balance in their mice. However, perhaps TonEBP functioned by causing a vascular endothelial growth factor-C mediated increase in lymph-capillary density, which could also facilitate restoring sodium balance [5]. Perhaps the sodium and chloride that were retained were stored nonosmotically by binding to proteoglycans or alternatively by other mechanisms in the skin [6]. Sodium and chloride storage can be measured with considerable accuracy by taking the carcasses apart, precision weighing before and after ashing of the tissues, and atomic absorption spectrometry of cation concentrations.
Chloride can also be precisely quantitated. Thus, we could find out "where the salt went."

Respectfully,

Friedrich C. Luft

\section{References}

1. Soleimani M, Xu J (2006) SCL26 chloride/base exchangers in the kidney in health and disease. Semin Nephrol 26:375-385

2. Amlal H, Xu J, Barone S, Zahedi K, Soleimani M (2013) The chloride channel/transporter Slc26a9 regulates the systemic arterial blood pressure and renal chloride excretion. J Mol Med. doi:10.1007/s00109012-0973-1

3. Xu J, Henriksnäs J, Barone S, Witte D, Shull GE, Forte JG, Holm L, Soleimani M (2005) SLC26A9 is expressed in gastric surface epithelial cells, mediates $\mathrm{Cl}^{-} / \mathrm{HCO}_{3}{ }^{-}$exchange, and is inhibited by $\mathrm{NH}_{4}^{+}$. Am J Physiol Cell Physiol 289:C493-C505

4. Geller DS (2010) Clinical evaluation of Mendelian hypertensive and hypotensive disorders. Semin Nephrol 30:387-394

5. Machnik A, Neuhofer W, Jantsch J, Dahlmann A, Tammela T, Machura K, Park JK, Beck FX, Müller DN, Derer W et al (2009) Macrophages regulate salt-dependent volume and blood pressure by a vascular endothelial growth factor-C-dependent buffering mechanism. Nat Med 15:545-552

6. Titze J, Shakibaei M, Schafflhuber M, Schulze-Tanzil G, Porst M, Schwind KH, Dietsch P, Hilgers KF (2004) Glycosaminoglycan polymerization may enable osmotically inactive $\mathrm{Na}^{+}$storage in the skin. Am J Physiol Heart Circ Physiol 287:H203-H208 